\title{
ACEITAÇÄO, EMPATIA E ENVOLVIMENTO EMOCIONAL NO RELACIONAMENTO ENFERMEIRA-PACIENTE
}

\author{
Maguida Costa Stefanelli * \\ Evalda Cançado Arantes** \\ Ilza Marlene Kuae Fukuda*
}

STEFANELl.I, M. C.; ARANTES, E. C.; FUKUDA, I. M. K. Aceitação, empatia e envolvimento emocional no relacionamento enfermeira-paciente. Rev. Esc. Enf. USP. São Paulo, $16(3): 245-253,1982$.

Ao interagir com paciente a enfermeira tem que ter sempre em mente que está sc relacionando com um ser humano. Neste relacionamento pessoa a pessoa há aspectos básicos indispensáveis ao conhecimento da enfermeira para tornar terapêutico aquele processo. Entre estes aspectos temos aceitação, empatia e envolvimento emocional. Estes foram abordados quanto a revisão bibliográfica, conceituação teórica ' importância para o relacionamento enfermeira-paciente. São descritas situaçóes que 'videnciam a ocorrência dos aspectos citados e os beneficios que estes trouxeram para a interaçào enfermeira-paciente.

\section{ACEITAÇÃO}

Ao desenvolver relacionamento terapêutico com o paciente a enfermeira deve ter sempre em mente que está interagindo com um ser humano - o paciente ou cliente. Esta condição, de paciente ou cliente, já implica em mudança para a pessoa; e como toda mudança traz consigo certo grau de ansiedade, esta pode levar o paciente ou cliente a apresentar padrões de comportamento não aceitos socialmente.

É uma pessoa nessas condições que a enfermeira, em geral, encontra no desempenho de suas funções. Para que ela consiga assistir o paciente de modo eficaz é preciso que desenvolva aceitação genuína do paciente. Aceitação esta que para MASLOW (1970) representa uma das necessidades básicas do ser humano. Segundo PASQUALI et alii (1981), a necessidade de ser aceito assume especial importancia para o paciente psiquiátrico, por causa de suas traumáticas experiências passadas.

* Professor Assistente do Departamento de Enfermagem Materno - Infantil e Psiquiátrica da Escola de Enfermagem da USP - disciplina Enfermagem Psiquiatrica. Mestre em Enfermagem. Enfermeira.

** Professor Assistente Doutor do Departamento de Enfermagem Materno - Infantil e Psiquítrica da Escola de Enfermagem da USP - disciplina Enfermagem Psiquiátrica. Doutor em Enfermagem. Enfermeira. 
Aceitar o paciente não é somente compreendê-lo; é também considerá-lo como ser humano, com sentimentos e valores que lhe são peculiares e que determinam suas atitudes, expressas em seu comportamento (CONNOLLY, 1960).

Aceitar não implica em concordar com o comportamento do paciente; implica em tomar consciência do significado do comportamento não aceito socialmente. Demonstrar aceitação pelas manifestações de comportamento do paciente, no momento em que ele as expressa, leva-o a sentir-se aceito como pessoa e portanto mais seguro e confiante.

A enfermeira deve, porém, estabelecer limites ao comportamento do paciente, com tato e firmeza, considerando que ele é um ser humano e que seu comportamento é decorrente de uma condição patológica. Atuando deste modo estará trabalhando com o paciente para que este desenvolva padrões de comportamento mais aceitos do ponto de vista social.

Dizer, simplesmente, ao paciente que o aceita e o compreende como pessoa não é suficiente para que ele perceba estes sentimentos no relacionamento; a enfermeira deverá demonstrar ao paciente que ela é um elemento participante na interação. Poderá dizer-lhe que o compreende, que o está ouvindo; entretanto, para que transmita ao paciente o sentimento de ser aceito tal como ele é com seus direitos, deveres, capacidades e limitações, é necessário que ela já tenha desenvolvido intimamente esta aceitação como parte integrante de sua atitude em relação ao paciente.

O desenvolvimento da atitude de aceitação por outra pesoa só é possivel quando a enfermeira aceita-se a si própria como pessoa e compreende que também, tem forças e fraquezas.

O conceito operacional de aceitação, elaborado por WALLACE (1967), permite melhor compreensão desta; uma pessoa, a enfermeira, torna-se consciente do comportamento de outra pessoa, o paciente, e sente-se impelida a reagir a este comportamento. Emerge, então, uma mudança que caracterizará o tipo de aceitação que poderá ocorrer; ou um tipo que constitui um processo automático de aceitação ou um desafio à mesma. Quando o comportamento expresso pelo paciente está de acordo com os valores e expectativas da enfermeira, ocorre a chamada aceitação automática; mas caso o comportamento manifestado pelo paciente não esteja de acordo com o esquema de valores da enfermeira, surge uma situação de conflito. Esta ocorre porque a enfermeira introjeta, durante sua formação profissional, a idéia de que a aceitação deve ser irrestrita e o paciente não pode ser rejeitado. A enfermeira, para resolver esta situação, precisa analisar sua atitude em relação ao comportamento do paciente e reconhecer as diferenças entre os seus padrões de comportamento e os dele; precisa respeitá-lo como ser humano, permitindo que ele se comporte de acordo com seus próprios valores, mas ao mesmo tempo reforçar suas manifestações sadias de comportamento; 
fazendo-o sentir sua compreensão e seu calor humano a enfermeira contribuirá para que o paciente se sinta aceito.

O sentimento de ser aceito pela enfermeira ajuda o paciente a atuar de maneira construtiva, sem atitudes de defesa indesejáveis. Ao desenvolver aceitação pelo paciente a enfermeira deve acautelar-se para não demonstrar atitude de aprovação ou reprovação; ao mesmo tempo deve estar atenta para não estabelecer com ele relacionamento desumano e despersonalizado, pois, neste caso, a enfermeira não só deixa de exercer julgamento como também deixa de perceber o paciente como uma pessoa (CONNOLLY, 1960; WALLACE, 1967; HAYS \& LARSON, 1970; WRIGHT \& BURGESS, 1981).

Para PEPLAU (1952) e TRAVELBEE (1963) o fato do paciente sentir-se aceito, na fase em que ele e a enfermeira trabalham juntos na resolução de problemas já identificados, é um dos resultados mais importantes desta etapa.

\section{EMPIATIA}

Se a enfermeira desejar que, na sua interação com o paciente, as relações tornem-se realmente terapêuticas, ela deve tentar sentir a experiência deste, tal como ele a percebe. A essa capacidade de tentar ver o mundo como, outra pessoa o vê, sem perder a própria identidade, é dado o nome de "empatia" (KALISCH, 1973; NORTHOUSE, 1979; WILSON \& KNEISL, 1979; SPY, 1981).

É por meio do sentimento empático que a enfermeira transmite ao paciente a sensação de que ele é aceito.

Segundo MANSFIELD (1973), a compreensão e a aceitação empática do paciente só têm valor quando estas lhe são transmitidas, tanto pela comunicação verbal como pela não verbal. À essa transmissão dá-se o nome de comunicação empática.

A percepção empática nem sempre é acurada, mas o que importa é a enfermeira comunicar ao paciente que está tentando compreendê-lo, mesmo quando as idéias dele estão em desacordo com as suas.

A empatia é colocada por MANSFIELD (1973) e KALISCH (1973), entre outros, como condição básica para o relacionamento de ajuda. Estes autores a consideram como um dos elementos responsáveis pelos resultados do relacionamento terapeuta-paciente.

SULLIVAN (1953) diz ser o sentimento empático uma das primeiras características do relacionamento da criança com as pessoas que a cercam. O citado autor a descreve como uma sensação afetiva que a criança demonstra no relacionamento interpessoal com as pessoas que lhe são significativas (mãe, babá); cita, como exemplo, a ansiedade que se percebe na criança quando a mãe está ansiosa, não encontrando outra explicação para este fenômeno. Basta observar-se atentamente 
a relação mãe-filho para se perceber que a empatia, como o citado autor a conceitua, realmente ocorre, a despeito da obscuridade do processo.

A empatia é muitas vezes confundida com simpatia; esta, porém, se dá de modo inconsciente e faz com que a enfermeira estabeleça analogia entre a própria situação e a do paciente, levando-a a perder a objetividade em seu relacionamento com ele. É comum surgirem, associados à simpatia, sentimentos de pena, aprovação e reprovação, portanto não terapêuticos (TRAVELBEE, 1963; EHMANN, 1971 e WILSON \& KNEISL, 1979).

A empatia se dá num nivel consciente e, como dizem TRAVELBEE (1963) e CREWS (1979), é basicamente uma operação intelectual combinada com um esforço dirigido para a compreensão do outro. É comum ouvir que a empatia só ocorre, realmente, quando a pessoa envolvida já experimentou todas as situações pelas quais o paciente passa; mas, como afirmam HOFLING et alii (1970), esta é uma habilidade a ser desenvolvida, pois, é difícil, ou mesmo impossivel, encontrar uma enfermeira que já tenha vivenciado todas experiencias dos pacientes sob seu cuidado. Não se pode vivenciar tudo o que o paciente experimenta, mas é essencial a enfermeira reconhecer que a experiência do paciente ocorre do modo como ele a descreve.

ZDERARD (1969) afirma que a flexibilidade e a espontaneidade são fatores que promovem a empatia.

Para ajudar alunos de enfermagem e enfermeiras a desenvolverem acurado e alto grau de empatia, BAUMGARTNER (1970) recomenda a análise operacional de empatia; apresenta este processo em várias etapas e afirma que para isto a enfermeira deverá: 1. aceitar-se a si mesma; 2 . desenvolver habilidade em se concentrar nos problemas do paciente; 3 . tentar participar da experiência do paciente como ele a vivencia; 4 . ser capaz de tolerar a ansiedade disto resultante; 5 . analisar os problemas do paciente e identificar soluções alternativas sem fazer julgamento de valor a respeito dos sentimentos do paciente; e 6 . participar dos sentimentos do paciente, na sua atual condição de vida, sem perder a objetividade.

Para o desenvolvimento destas etapas é exigido considerável nível de maturidade emocional e intelectual. O tempo necessário para que ocorra o sentimento empático e a extensão na qual ele ocorre variam de enfermeira para enfermeira; está, também, relacionado com as experiências prévias da enfermeira, como profissional e como pessoa.

Serão descritas a seguir duas situações que deixam evidente a importância da aceitação e da empatia no relacionamento enfermeira-paciente.

Uma paciente internada em uma unidade psiquiátrica permanecia isolada, não conversava com as outras pacientes nem com as pessoas da equipe que a assistia; uma aluna de enfermagem interessou-se por 
ela e passou a permanecer a seu lado, demonstrando disponibilidade para ajudá-la. Gradativamente foi aumentando o tempo de permanência a seu lado na tentativa de mostrar à paciente que a aceitava como pessoa, independentemente de seu comportamento; de vez em quando a convidava para participar de alguma das atividades desenvolvidas na unidade mas não obtinha resposta verbal; a comunicação não verbal da paciente - expressão facial - transmitia um constante pedido de ajuda; no sexto dia de interação aluna-paciente, aproximadamente após dez dias do início das interações, a paciente segurou a mão da aluna e disse: "Meu médico não vem me ver e, quando vem, quase não fala comigo... Não recebo visita, ontem não veio ninguém outra vez".

A aluna, que já fora internada em uma clínica médica, foi capaz de se colocar no lugar da paciente com relativa facilidade; conversou com o médico da paciente, expôs a situação da mesma e sugeriu-lhe que a visse com mais freqüência; simultaneamente entrou em contato com a assistente social para que esta tentasse saber o que estava acontecendo com os familiares da paciente. A aluna comunicou à paciente as medidas que havia tomado em seu benefício. A partir de então, a paciente começou a responder às perguntas que lhe eram feitas e a participar de atividades junto a outras pacientes.

Outro exemplo é o de uma paciente internada em uma unidade de clínica médica, de um hospital geral. A paciente estava sendo assistida exatamente como fora planejado, porém, não apresentava remissão de sintomas e não demonstrava interesse em se curar; chegou a manifestar idéia de suicídio, por várias vezes. Foi nesta situação que uma das enfermeiras da unidade começou a interagir com a paciente; em todas as suas ações a enfermeira demonstrava interesse e aceitação pela paciente; foi, assim, capaz de transmitir a esta que acreditava na sua recuperação e que estava disposta a ajudá-la. Isto foi percebido pela paciente que, paulatinamente, foi-se esforçando por cooperar de modo mais efetivo na sua recuperação. Esta aceitação genuína e o sentimento empático desenvolvido pela enfermeira foram percebidos, não só pela paciente como, também, por seus familiares que mudaram de comportamento em relação à doença e recuperação da paciente.

\section{ENVOLVIMENTO EMOCIONAL}

Há enfermeiros que utilizam todos os procedimentos indicados para assistir um paciente mas são incapazes de demonstrar interesse e aceitação da sua pessoa; conseqüentemente, não conseguem individualizar a assistência prestada. Isto porque não atendem a um aspecto de vital importância para o processo de relacionamento terapêutico enfermeira-paciente - o envolvimento emocional.

Como o relacionamento terapêutico é uma seqüência de interações entre enfermeira e paciente, durante um certo tempo, é natural que surja entre eles um certo grau de participação emocional. A enfer- 
meira è um ser humano e, como tal, tem sentimentos e emoções. $\mathrm{O}$ envolvimento emocional deve ocorrer se a enfermeira desejar ser verdadeiramente útil ao paciente, porém, em nível terapêutico. Para isto é importante que ela analise constantemente suas próprias atitudes, seu comportamento e sentimentos, de modo a não perder a objetividade.

$\dot{E}$ difícil para o aluno aceitar o envolvimento emocional com o paciente como sendo terapêutico, porque, em geral, ele só ouve dizer: "não se envolva com os problemas do paciente" ou "interaja com o paciente de modo objetivo". Na disciplina Enfermagem Psiquiátrica o aluno é orientado a interagir com o paciente de modo terapêutico e a esforçar-se por compreender as necessidades do paciente. Como o aluno poderá manter-se neutro e ao mesmo tempo envolver-se a ponto de se preocupar com o paciente, como uma pessoa e não como um conjunto de sintomas?

Para que o envolvimento emocional seja mantido em níveis terapêuticos. é necessário que a enfermeira reconheça o fato de que ela é um elemento participante do relacionamento; deve estar consciente de seus sentimentos e das emoções que estão ocorrendo na situação. Essa análise do envolvimento na situação é uma das tarefas mais difíceis da enfermeira porque é muito mais cômodo para ela evitar o envolvimento com o paciente. Com isto ela não experimentará ansiedade em relação ao ser humano necessitado de ajuda (PASQUALI et alii, 1981; TRAVELBEE, 1969).

E essencial que a enfermeira esteja consciente do grau de envolvimento que está ocorrendo na interação com o paciente, e de que as necessidades que devem ser satisfeitas são as do paciente e não as suas; ela deve ser capaz de dar alguma coisa de si, dedicar um certo tempo ao paciente, preocupar-se e demonstrar interesse por ele sem nada exigir em troca; deve ser capaz de permitir que o paciente necessite cada vez menos dela, à medida que recupera a saúde, ao invés de mantê-lo dependente dela (HOLMES, 1960; TRAVELBEE, 1963; PASQUALI et alii, 1981).

Para que envolvimento seja mantido em nível terapêutico, a enfermeira deverá discutir os eventos deste relacionamento com outra pessoa que tenha, no mínimo, a mesma formação que ela; isto se faz, ainda, mais necessário quando se trata de aluno ou de enfermeira principiante, que não tem experiência suficiente para assumir plena responsabilidade pela assistência de enfermagem ao paciente, principalmente quando este manifesta problema mental; daí a necessidade de supervisão direta e individual nestes casos.

Para que o envolvimento emocional, no relacionamento enfermeira-paciente, seja realmente útil, é necessário que: o interesse da enfermeira esteja voltado inteiramente para o paciente; os objetivos do relacionamento estejam claros para ambos; a enfermeira esteja consciente de seu papel terapêutico; a enfermeira utilize seus conhecimentos e habi- 
lidades em técnicas terapêuticas de comunicação; a enfermeira avalie constantemente sua atuação considerando os sentimentos e a emoção que estão ocorrendo.

Vemos, portanto, que o envolvimento emocional compreende aspectos tanto afetivos como cognitivos; e que ela depende de características próprias da estrutura da personalidade das pessoas que participam do relacionamento.

Como exemplo de uma situação onde ocorreu o envolvimento emocional podemos citar o caso de uma aluna que desenvolvia relacionamento terapêutico com paciente da sua idade, também estudante universitária, internada em uma clínica psiquiátrica; a aluna ouvia a paciente dizer a todo instante que não estava mais doente e que, provavelmente, seria reprovada se continuasse internada; a aluna começou a achar que a paciente, mesmo estando na fase aguda da doença, já não precisava mais da internação hospitalar; passou, então, a defendê-la dizendo que ela, já não estava mais doente, e começou a culpar o médico pela provável reprovação da paciente. Foi necessária a intervenção da docente, responsável pela orientação da aluna, para mostrar a esta que a paciente ainda apresentava sintomas evidentes da doença. Após a orientação a aluna percebeu que estava ocorrendo um envolvimento bastante prejudicial à objetividade do relacionamento terapêutico.

Apesar do envolvimento ser imprescindível ao relacionamento terapêutico, para que seja útil é necessário que a objetividade seja mantida durante todo o processo, isto é, que a enfermeira seja capaz de considerar todos os acontecimentos sem reagir de forma pessoal, analisando-os o mais realisticamente possível (TRAVELBEE, 1969; HOFLING et alii, 1970).

\section{CONSIDERAÇŐES FINAIS}

E importante considerar que, embora o relacionamento enfermeira-paciente deva ser terapêutico, outros sentimentos como a rejeição e o não envolvimento emocional podem surgir, pois a enfermeira, como um ser humano, também pode ter problemas emocionais não superados que venham interferir em sua atuação profissional; quando estes ocorrem, a enfermeira deve ser auxiliada na análise realística de suas atitudes e seu comportamento, para verificar porque aqueles sentimentos estão ocorrendo e o que poderá ser feito para promover o seu desenvolvimento no processo de maturação; se após a análise objetiva, a enfermeira não for capaz ainda de superar os problemas que os originaram, deverá mudar de paciente para não prejudicá-lo, encaminhando-o a outra colega. O essencial é que a enfermeira tenha condições para analisar as diversas situações interpessoais que encontra na sua vida pessoal ou profissional, nas quais poderão ocorrer os fenômenos aceitação, empatia e envolvimento emocional.

Entre os profissionais que atuam na área da psiquiatria, é comum surgir discussões para saber se os fenômenos empatia e envolvimento 
emocional ocorrem simultaneamente ou qual deles ocorre em primeiro lugar. Para alguns é necessário primeiro envolver-se emocionalmente com o paciente a fim de poder sentir empatia em relação a ele; no caso de outros, o sentimento empático é uma condição para que ocorra o envolvimento emocional. O importante, porém, é estar ciente de que esses fenômenos ocorrem em diferentes graus, de acordo com a experiência prévia de cada pessoa.

Para finalizar convém ressaltar a importância dos conceitos aqui emitidos em qualquer área de atuação da enfermeira.

DiVICENTI (1977) coloca a empatia, o envolvimento emocional e a objetividade entre os aspectos básicos para a liderança que é essencial para o desempenho da enfermeira.

FORSYTH (1980) destaca a necessidade das enfermeiras aprofundarem-se no estudo da empatia; declara que a compreensão e o uso deste conceito facilitam o desenvolvimento de teorias de enfermagem que influenciam o curso do desenvolvimento profissional.

STEFANELLI, M. C.; ARANTES, E. C.; FUKUDA, I. M. K. Acceptance, empaty and emotional involvement in nurse-patient relationship. Rev. Esc. Enf. USP, São Paulo, $16(3): 245-253,1982$.

In dealing with the patient, the nurse has always to have in mind that she is dealing with a human being. There are basic aspects in this personal relationship needed to the knowledge of the nurse to make this process therapeutic. Among these aspects we have acceptance, empaty and emotional involvement. These aspects we studicd following bibliographical review, theorical conception and importance to the nurse-patient relationship. Situations that show accourance of those given aspects and the benefits brought to nursc-patient relationship are described.

\section{REFERENCIAS BIBLIOGRAFICAS}

BAUMGARTNER, M. Empathy. In: CARLSON, C. E. Behavioral concepts \& nursing intervention. 2. ed. Philadelphia, J.B. Lippincott, 1970. cap. 2, p. 29-37.

CREWS, N. E. Developing empathy for affective communication. AORN J., Denver, 30(31): 536, 540-6, Sept. 1979.

DIVICENTI, M. Administering nursing service. 2. ed. Boston, Little Brown, 1977.

EHManN, V. E. Empathy: its origin, characteristics and process. Perspect. Paychiat. Care, Hillsdale, 9(2) 72-80, 1971.

FORSYTH, G. L. Analisis of the concept of empathy: illustration of one approach. ANS, Germantown, 2(2):33-42, 1980.

CONNOLLY, M. G. What acceptance means to patients. Am. J. Nurs., New York, 60(12): 1754-7, 1960 .

IIAYS, J. S. \& LARSON, K Interpersonal techniques. In: - Interacting with patients. New York, Macmillan, 1970. cap. 1, p. 6-38.

HOFLING, C. K. et alli. Compreensión de las relaciones entre enfermera y paciente. In: Enfermería psiquíatrica. 2. ed. México, Interamericana, 1970. cap. 3, p. 23-60.

HOLMES, M. What's wreng with getting involve? Nurs Outlook, New York, 8:250-1, May, 1960. 
KALISCH, B. J. What is empathy? Am. J. Nurs., New York, 73(9):1548-62, Sept. 1973.

MANSFIELD, E. Emphaty: concept and identified psychiatric nursing behavior, Nurs. Res., New York, 22(6):525-30, Nov./Dec. 1973.

MASLOW, A. A thecry of humar motivation. In: Motivation and personality. 2. ed. New York, Harper \& Row, 1570. cap. 4, p. 35-58.

NORTHOUSE, P. G. Interpersonal trust and empathy in nurse relationship. Nurs. Res., New York, 28(6):365-8, Nov./Dec. 1979.

PASQUALI, E. A. et alii. The matrix of psychosocial intervention. In: health nursing. A bio-psycho-cultural approach. St. Louis, C. V. Mosby, 1981. cap. 6, p. 208-51.

PEPLAU, $H$. Phases of nurse-patient relationships. In: nursing. New York, Putnam's sons, 1952. cap. 2, p. 17-42.

Interpersonal relations in

SULLIVAN, H. S. Postulates. In: York, Norton, 1953. cap. 3, p. 31-45.

SPY, T. So you think you know about counselling? Nurs. Times, London, 77(21):917-20, May, 1981.

TRAVELBEE, J. Aspects of the one-to-one relationship. In: Intervention in psychiatric nursing: process in the one-to-one relationship. Philadelphia, Davis, 1969. cap. 3 , p. 47-54.

TRAVELBEE, J. What do we mean by rapport? Am. J. Nurs., New York, 63(2):70-2, Feb. 1963.

WALLACE, C. O. Acceptance. In: CONFERENCE ON TEACHING PSYCHIATRIC NURSING IN BACCALAUREATE PROGRAMS. Atlanta, Southern Regional Education Board, 1967. p. 10-17.

WILSON, H. S. \& KNEISL, C. R. The nurse's personal integration and ethics. In: Psychiatric nursing. Menlo Park, Addison-Wesley, 1979. cap. 3, p. 44-71.

WRIGHT, E. M. \& BURGESS, A. W. Nurse patient interaction. In: BURGESS, A. W. Psychiatric nursing in the hospital and the community. Englewood Cliffs, Prentice. Hall, 1981. cap. 5, p. 52-74.

ZDERARD, L. T. Empatic nursing. Realization of a human capacity. Nurs. Clin. North Am., Philadelphia, 4(4):655-62, Dec. 1969 